\title{
PROCESS OPTIMIZATION OF CAST ALLOY 718 FOR WATER COOLED GAS TURBINE APPLICATION
}

\author{
G.K. Bouse ${ }^{+}$and P.W. Schilke ${ }^{*}$ \\ General Electric Company ${ }^{+}$Materials and Processes Laboratory, and \\ Gas Turbine Products Division, Schenectady N.Y. 12345
}

Several quantitative tools were utilized to optimize the microstructure of cast alloy 718 . Quantitative metallography indicated that the cast structure can contain about $11 / 2$ volume \% carbide and nitride phase, about 0.4 volume \% porosity and up to about 17 volume $\%$ Laves phase, a $\mathrm{Cb}$ rich segregant that readily forms in this alloy. With the proper hot isostatic pressing (HIP) cycle, segregation and porosity could be reduced to zero percent, allowing ultimate tensile strengths up to $1240 \mathrm{MPa}(180 \mathrm{Ksi})$ to be obtained. Furthermore, differential thermal analysis showed that with the presence of Laves phase, an incipient melting point $100^{\circ} \mathrm{C}\left(180^{\circ} \mathrm{F}\right)$ below the true melting point was possible. HIP was also shown to increase the rate of homogenization. A dislocation structure was documented that is thought to contribute to the increased strength of the alloy. It was found that $\gamma$ " nucleated on the dislocation lines, separating the original cast grain into tiny subgrains. These subgrains were determined by TEM to be misoriented $\sim 10-12^{\circ}$ between themselves, effectively reducing the grain size to $10-20$ microns from the original grain size which was determined to be $\sim 3000$ microns.

\section{INTRODUCTION}

The High Temperature Turbine Technology (HTTT) phase II contract awarded to the General Electric Company by the Department of Energy is directed toward component design, fabrication and technology testing of critical hot gas path parts. The overall goal of the HTTT program is to develop a land-based gas turbine which can burn a coal derived fuel at $1427^{\circ} \mathrm{C}\left(2600^{\circ} \mathrm{F}\right)$ with a growth capability to $1649^{\circ} \mathrm{C}\left(3000^{\circ} \mathrm{F}\right)$. This would result in a significant jump in the firing temperature of current turbines (1). To accomplish this a water cooled design approach was chosen. In this design approach, the components maximum metal temperatures will be maintained at 
$538^{\circ} \mathrm{C}\left(1000^{\circ} \mathrm{F}\right)$ or lower, to maximize efficiency in a combined cycle mode and to minimize the impact of both corrosion and performance degradation due to reduction of nozzle throat area (caused by ash buildup). This will result in average metal temperatures in the range of $204-454^{\circ} \mathrm{C}\left(400-850^{\circ} \mathrm{F}\right)$.

The 2nd stage nozzle is one of the critical parts selected for fabrication and testing during this phase II program. Nickel base alloy 718 is the material selected for the component to satisfy the required thermal strain capability, corrosion resistance and fabricability requirements. The processes identified for the manufacture of this component include advanced investment casting, hot isostatic pressing (HIP), conventional and EDM machining, Shaped Tube Electrolytic Machining (STEM) drilling, brazing and welding, which have been discussed in detail elsewhere (2). To insure the successful fabrication and testing of the component, work was performed to optimize the microstructure. This paper describes the development that went into the selection of HIP and heat treat cycles, and discusses the effect of lliese cycles on the alloy microstructure and resultant tensile properties.

\section{MATERIAL AND HEAT TREATMENTS}

The compositions used in this investigation are listed in Table I. Bars $36 \mathrm{~mm}$ (1.44 in) in diameter were used in the microstructure optimization work. Note that the C and Al levels are slightly higher than normally encountered in gas turbine casting specifications, however they were deemed acceptable for the purpose of this investigation. Spot checks were made using specification material slabs $25 \mathrm{~mm}(1 \mathrm{in})$ thick and the chemistry difference noted above was found to be negligable. The material used for tensile properties was in the form of cast to size (CTS) tensile bars with a reduced section nominally $7 \mathrm{~mm}$ (.25 in) in diameter which had a chemistry typical of that used for gas turbine parts. All materials were vacuum investment cast according to normally accepted practice.

Heat treating for the high temperature studies was accomplished using à vacuum furnace capable of $10^{-5}$ torr, or a HIP furnace using commercially pure

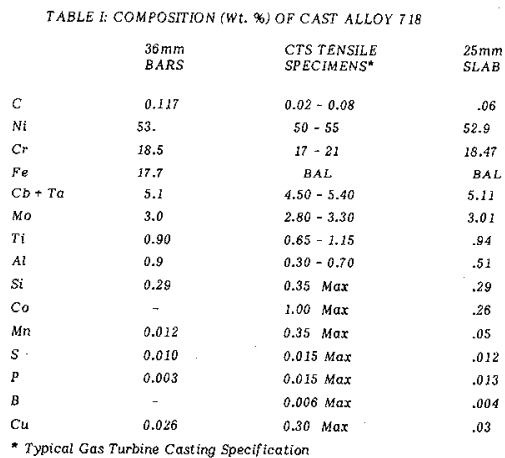
argon as the pressure media. 
Temperatures of $1172^{\circ} \mathrm{C}\left(2142^{\circ} \mathrm{F}\right), 1200^{\circ} \mathrm{C}\left(2192^{\circ} \mathrm{F}\right), 1213^{\circ} \mathrm{C}\left(2217^{\circ} \mathrm{F}\right)$ and $1228^{\circ} \mathrm{C}\left(2242^{\circ} \mathrm{F}\right)$ for times of 1,2 and 4 hours were used to study the homogenization rate of the alloy. A cooling rate of $500-555^{\circ} \mathrm{C}$ $\left(900-1000^{\circ} \mathrm{F}\right) / \mathrm{hr}$. to $760^{\circ} \mathrm{C}\left(1400^{\circ} \mathrm{F}\right)$ and then cool to room temperature was used throughout the study for consistency. The material used to spot check this data received the traditional $1093^{\circ} \mathrm{C}$ $\left(2000^{\circ} \mathrm{F}\right) / 1 \mathrm{hr}$ "homogenization" followed by a $954^{\circ} \mathrm{C}\left(1750^{\circ} \mathrm{F}\right) / 1 \mathrm{hr}$. "solution" and the dual cycle aging treatment which consists of $718^{\circ} \mathrm{C}$ $\left(1325^{\circ} \mathrm{F}\right) / 8 \mathrm{hrs}$, cool $55^{\circ} \mathrm{C}\left(100^{\circ} \mathrm{F}\right) / \mathrm{hr}$ to $621^{\circ} \mathrm{C}\left(1150^{\circ} \mathrm{F}\right)$ and hold an additional 8 hours and air cool to room temperature. The CTS tensile specimens, were HIP'd at $1200^{\circ} \mathrm{C}\left(2192^{\circ} \mathrm{F}\right) / 4 \mathrm{hrs}$., cooled to R.T. and given the dual cycle age.

\section{OPTIMIZATION OF CAST MICROSTRUCTURE}

Thermal processing of the microstructure was directed toward the elimination of porosity, and Laves phase. Laves phase, topologically closed packed with a hexagonal structure represented by the type $\mathrm{MgZn}_{2}$, is rich in $\mathrm{Cb}$ (3). Originally referred to as "freckles", the presence of this phase, which is primarily due to ingot solidification segregation, is generally regarded as deleterious to the mechanical properties.

\section{Experimental}

Quantitative Metallography (QM). Using the Bausch and Lomb Omnicon Image Analysis System FASII, one hundred fields, each an area $0.37 \mathrm{~mm}^{2}\left(0.00058\right.$ in $\left.{ }^{2}\right)$ from a sample space of $13 \mathrm{~mm}(.5 \mathrm{in})$ by $25 \mathrm{~mm}$ ( 1 in) was scanned from the metallographic mounts. The polishing procedure is one of almost complete automation $(4,5)$, finishing up on the 0.3 micron alumina wheel. Each specimen was scanned once in both the as-polished and etched condition. The etchant consisted of a $\mathrm{HF}: \mathrm{HNO}_{3}: \mathrm{H}_{2} \mathrm{O}$ solution at room temperature having a ratio of 1:2:7 by volume. Each specimen was immersed 12 minutes without swabbing.

Separation of three "phases", namely the porosity (black), carbides (gray) and nitrides (pink) in the otherwise white matrix was accomplished using contrast control on the as-polished mount. After etching, the Laves phase becomes gray and the scan is repeated. Subtraction of the first scan from the second scan then allows the amount of Laves phase to be calculated. The repeatability of this method is estimated to be $\sim 0.1 \%$. The results of the QM work are shown in Figure 1. It was found that while significant homogenization occurred in one hour at temperature, complete homogenization did not occur until 4 hours at temperature. Porosity 
however was only slightly reduced in one hour, and required two hours for complete closure.

The two lowest HIP temperatures gave nearly identical results, and are plotted in Figure 1 as single $1200^{\circ} \mathrm{C}\left(2192^{\circ} \mathrm{F}\right)$ results. The specimens that were used in the $1213^{\circ} \mathrm{C}\left(2217^{\circ} \mathrm{F}\right)$ HIP study were spot checked by normal visual metallography, so sufficient data was not collected to allow generalizations. Four hours at this temperature did however fully homogenize the structure. HIP cycles at $1228^{\circ} \mathrm{C}$ $\left(2242^{\circ} \mathrm{F}\right)$ did not allow any homogenizing to occur, leaving the Laves phase with the appearance of a eutectic structure. This is thought to be due to incipient melting.

To compare the "rates" of homogenization at low pressure, several specimens were heat treated in a vacuum furnace. The results are plotted as a dashed line in Figure 1. It was found that HIP did accelerate homogenization, which was determined to be due to porosity closure (making available more diffusion paths, since Laves phase is often associated with porosity), and due in part to an inadvertent $10^{\circ} \mathrm{C}\left(18^{\circ} \mathrm{F}\right)$ temperature difference between the HIP and vacuum furnace.

Differential Thermal Analysis (DTA). A Dupont Instruments 990 Thermal Analysis System equipped with a $1600^{\circ} \mathrm{C}\left(2912^{\circ} \mathrm{F}\right)$ furnace was used for this study. The specimen size was approximately $200 \mathrm{mg}$ and heating rates of $10^{\circ} \mathrm{C}\left(18^{\circ} \mathrm{F}\right) / \mathrm{min}$ were used according to well established procedures published elsewhere (6).

DTA thermograms were obtained from the HIP or heat treated specimens, to observe how the thermal cycles changed the melting characterstics of the alloy. It was found that the incipient melting point, or Laves solidus, varied as the amount of Laves phase present, Figure 2. After a HIP cycle of $1172-1200^{\circ} \mathrm{C}\left(2142-2192^{\circ} \mathrm{F}\right) / 1 \mathrm{hr}$, the Laves phase solidus increased to $1215^{\circ} \mathrm{C}\left(2220^{\circ} \mathrm{F}\right)$, indicating that homogenization was occurring. This was supported by QM which

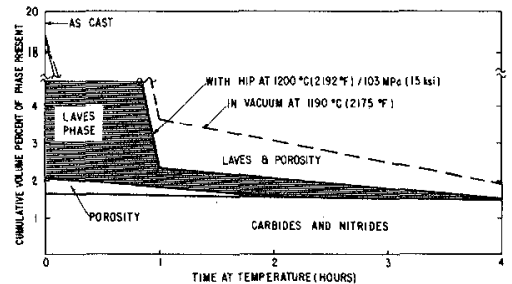

Fig. 1 Cumulative volume percent of phase present vs HIP or heat treat time.

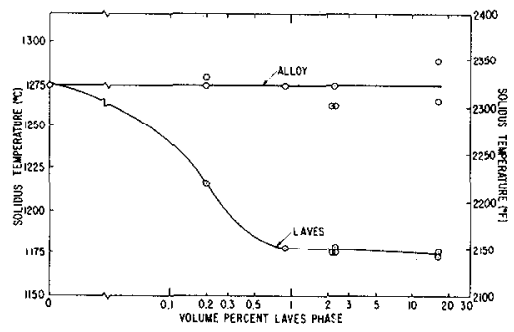

Fig. 2 Solidus temperature of alloy and Laves phase as a function of volume percent Laves phase. 
demonstrated that the amount of Laves phase also decreased to 0.2 vol. \%.The change in the Laves solidus further signifies that the composition of the phase is changing, a point that will be discussed in the next section. In the completely homogenized condition, Laves phase is eliminated and the Laves solidus coincides with the alloy solidus at $1272^{\circ} \mathrm{C}\left(2323^{\circ} \mathrm{F}\right)$.

For material in the as cast condition, the Laves solidus was $1175^{\circ} \mathrm{C}\left(2147^{\circ} \mathrm{F}\right)$ compared to the alloy solidus which averaged $1274^{\circ} \mathrm{C}\left(2323^{\circ} \mathrm{F}\right) \pm 15^{\circ} \mathrm{C}\left(27^{\circ} \mathrm{F}\right)$. The $1093^{\circ} \mathrm{C}\left(2000^{\circ} \mathrm{F}\right)$ cycle, used on the traditional material specification does not change this incipient melting temperature appreciably, indicating that it is no better than as cast material when it comes to homogenizing, although it does have less Laves phase $(2.3 \mathrm{vol} \%)$. This material is believed to have less Laves phase initially, as the amount of the phase is related to the cooling rate during initial solidification $(7,8)$. The $1093^{\circ} \mathrm{C}\left(2000^{\circ} \mathrm{F}\right)$ treatment is not believed to be significant concerning hornogenization, because Laves phase consists of large globular particles that are not thought to go into solution until $1162^{\circ} \mathrm{C}\left(2125^{\circ} \mathrm{F}\right)$ (3).

Microprobe Analysis. A Cameca probe unit with a scan speed of $8.3 \mathrm{microns}(0.002 \mathrm{in}) / \mathrm{min}$. on the as-polished metallographic mount was employed as the following elements were monitored; $\mathrm{Cb}, \mathrm{Ni}, \mathrm{Mo}$, $\mathrm{Cr}, \mathrm{Fe}, \mathrm{Ti}$ and $\mathrm{Al}$, which accounted for $98 \%$ of the elements present.

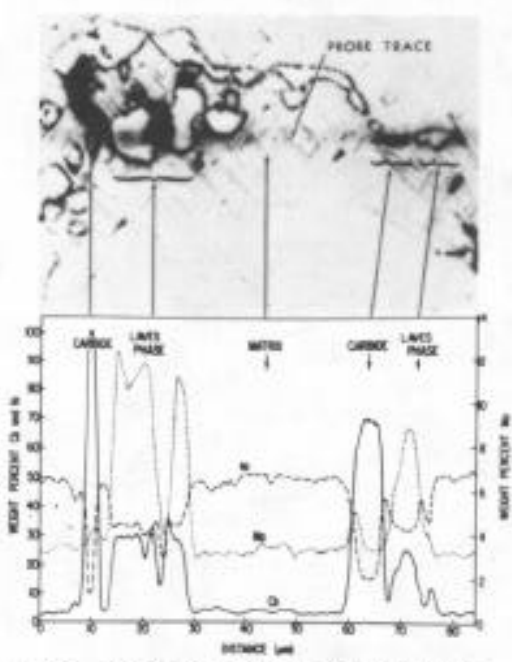

Fig. 3 Microprobe trace across Laves, carbide, and matrix phase shows the composition of $\mathrm{Ni}$, Mo, and $\mathrm{Cb}$ to vary significantily.
At least two scans were taken across Laves phase particles, where the longest dimension of the phase was at least twice as wide as the beam width, which was observed to be 3.5 microns $(0.0009$ in). A typical scan across the traditional heat treated specimen is shown in Figure 3, demonstrating the sensitivity of the three most variable elements, $\mathrm{Cb}, \mathrm{Ni}$ and $\mathrm{Mo}$.

The data confirms that as the Laves solidus begins to approach the alloy solidus, the composition of the phase begins to approach the matrix composition (Figure 4). Initially the composition of the phase was 34 wt $\% \mathrm{Ni}-28 \% \mathrm{Cb}$ $12 \% \mathrm{Mo}-12 \% \mathrm{Fe}-10.5 \% \mathrm{Cr}-0.5 \%$ $\mathrm{Ti}$ and $0.1 \% \mathrm{Al}$. Eventually when the phase disappeared, the composition became that of the 
matrix, which is nominally the wet chemistry reported. The $\mathrm{Cb}$ content of the matrix however was only about $3 \mathrm{wt} \%$ due to the high $\mathrm{CbC}$ content. The Laves solidus in fact was used to measure the homogeniety of the alloy. For example, the specimen HIP'd at $1200^{\circ} \mathrm{C}\left(2192^{\circ} \mathrm{F}\right) / 1$ hour was found to contain about 0.2 vol $\%$ of the phase, which has a solidus 4/10 of the difference between the lowest solidus $1175^{\circ} \mathrm{C}\left(2147^{\circ} \mathrm{F}\right)$ and the alloy solidus of $1274^{\circ} \mathrm{C}\left(2323^{\circ} \mathrm{F}\right)$. The "homogeniety" was then expressed as a percent difference between the fully homogenized alloy solidus temperature and the solidus temperature of the alloy containing greater than about 1 percent Laves. For the $100 \%$ homogenized condition, no Laves phase actually exists, and the composition shown in Figure 4 is the nominal composition of the matrix.

\section{MECHANICAL PROPERTIES}

\section{Results and Discussion}

Elevated Tensile Tests. Four heats of CTS tensile specimens were used to determine the elevated tensile properties of the optimized cast alloy 718 , and the average results are compared to the traditional properties obtained by Barker (7) in Figure 5. Although HIP'd vs non-HIP'd curves are compared, the reader should realize that the tensile strength will not change appreciably for small amounts of microporosity that may have existed in Barkers' specimens. Therefore the comparison is really between fully homogenized material vs material containing several percent Laves phase. For homogenized material it was found that in the temperature range
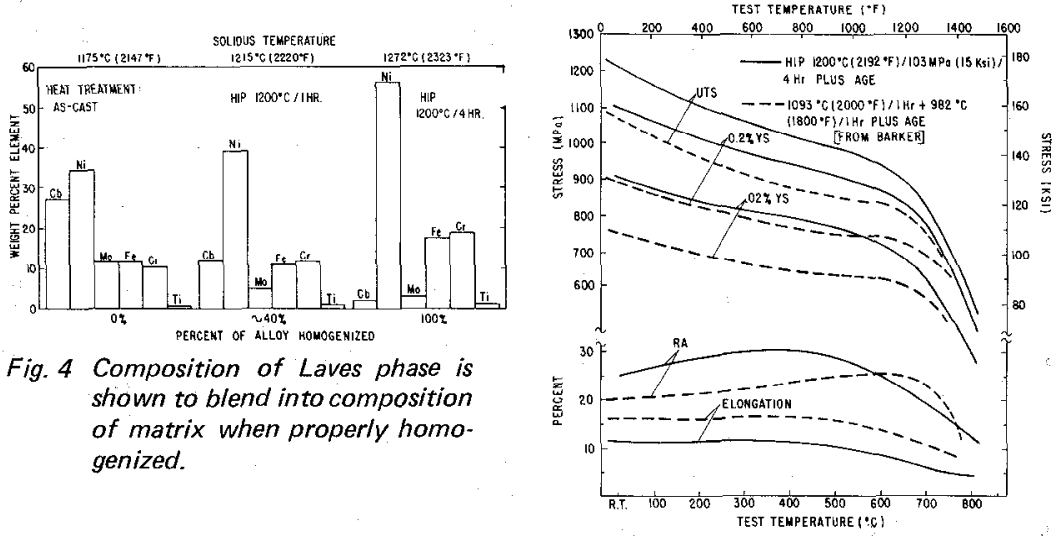

Fig. 5 Elevated tensile properties of properly homogenized alloy (solid lines) is compared to traditional data (dashed lines from ref. 7). of matrix when properly homogenized. 
from R.T. up to $650^{\circ} \mathrm{C}\left(1200^{\circ} \mathrm{F}\right)$ the UTS, $0.2 \%$ YS and $0.02 \%$ YS increased 10 to $20 \%$ over traditional values, while the reduction of area changed from an increase of $20 \%$ at RT to a decrease of $16 \%$ at $650^{\circ} \mathrm{C}\left(1200^{\circ} \mathrm{F}\right)$ and the elongation was reduced about $28 \%$ from the traditional heat treatment given the alloy. Reduction of tensile ductility is due to the tradeoff with matrix strength.

Subgrain Boundaries. In mechanical property studies done elsewhere (9) a fine network many times smaller than the as-cast grain size was observed. Such structures were also noted by the present authors, typical of Figure 6. The network was studied in an attempt to further optimize the mechanical properties, because the finer grain size in a cast product would certaintly have a beneficial effect in the temperature range of actual components. Investigations showed that a $1065^{\circ} \mathrm{C}\left(1950^{\circ} \mathrm{F}\right) / 1 \mathrm{hr}$ hold under pressure after the HIP homogenization cycle did not increase the network occurrence, but that reducing the cooling rate from $1833^{\circ} \mathrm{C}\left(3300^{\circ} \mathrm{F}\right) / \mathrm{hr}$ to $500^{\circ} \mathrm{C}$ $\left(900^{\circ} \mathrm{F}\right) / \mathrm{hr}$ did increase the occurrence of the network.

It was found by TEM microdiffraction studies that the network consists of $\gamma$ ", the primary strengthening phase (10). A second study (11) confirmed this and also found that a $\sim 10-12$ degree misorientation exists across the network, clearly establishing these regions as separate grains. Since it was concluded that the network was nucleating and growing in dislocations, any process that could increase the dislocation density would be advantageous, however such

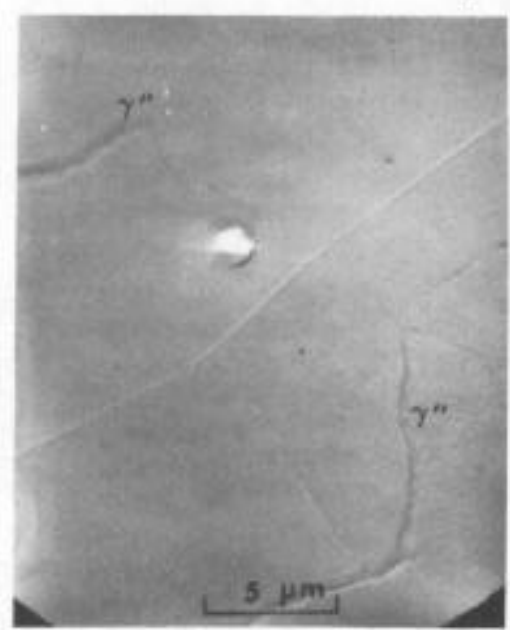

Fig. 6 TEM carbon replica showing ascast grain boundary and $\gamma^{\prime \prime}$ network. work was not implemented in the present study.

\section{CONCLUSION}

The optimization of the microstructure in cast alloy 718 must begin by elimination of porosity and casting segregation, which consists largely of Laves phase. Elimination of both is accomplished by use of HIP, in the temperature range of 1172 $1213^{\circ} \mathrm{C}\left(2142-2217^{\circ} \mathrm{F}\right)$ for at least two to four hours at a pressure of $103 \mathrm{MPa}$ (15 ksi). In doing so, the Laves phase, which initially contains 28 wt $\% \mathrm{Cb}$ diffuses into the general matrix, replenishing the $\mathrm{Cb}$ for the $\gamma^{\prime \prime}$ (strengthening phase) in the alloy. This results in 
a general 10-20\% increase in tensile strength given a specific age cycle. Parallel work has also shown that material in this condition can readily be machined, STEM drilled, brazed and welded.

\section{ACKNOWLEDGEMENTS}

The authors would like to acknowledge the support of this work by the DOE (contract EX-76-C-01-1806). The technical contributions from the following personnel will also be recognized: R. Betlejeski (Metallography); R. Matteson (QM and TEM); S. Duglin (DTA); T. Lamanec (Microprobe); and J. Treanor (Mech. Test.). G. Wasielewski, W. Schilling and S. Wlodek are also acknowledged for their technical guidance.

\section{REFERENCES}

1. A Caruvanna and W.F. Schilling "High Temperature Technology Program for a Water Cooled Gas Turbine" Proceedings of the Conference on Advanced Materials for Alternate Fuel Capable Directly Fired Heat Engines, Castine, Maine, August 1979.

2. P.W. Schilke, W.S. Blazek and W.F. Schilling, "Water Cooled Gas Turbine Monometallic Nozzle Development, ASME Trans, to be published (1980).

3. H.L. Eiselstein, "Advances in the Technology of Stainless Steels", ASTM STP 369, 1965, p62.

4. N.J. Gendron, Metals Engineering Quarterly, 13, (1), 1973 p13.

5. N.J. Gendron, Mounting, Lapping and Polishing Large Sizes and Quantities of Metallographic Specimens, Presented at Int'l. Mietallographic Society/ASM Joint Meeting, Beverly Hills, Ca., Sept. 23-24, 1973

6. G.E. Mauer, J. Domingue and W.J. Boesch, "Superalloy Design With Differential Thermal Analysis", Presented at the 27th Annual Meeting of the Investment Casting Institute, Chicago, Ill., October 11-13, 1979.

7. J.F. Barker, Metal Progress 81, 1962, p72.

8. J. Gordine, Welding Journal R.S. 49, 1970 p531-S.

9. W.H. Schweikert, "Manufacturing Methods for Production of Premium Quality Castings at a Lower Cost, AFML Contract F33615-76-C-5076 (1977)

10. A.M. Ritter General Electric Co. Corporate Research and Development Center, unpublished research.

11. J.C. Williams and N.T. Nuhfer, Carnegie Mellon University, unpublished research. 